\title{
Can a self-efficacy-based intervention decrease burnout, increase engagement, and enhance performance? A quasi-experimental study
}

\author{
Edgar Bresó • Wilmar B. Schaufeli • Marisa Salanova
}

Published online: 29 April 2010

(C) The Author(s) 2010. This article is published with open access at Springerlink.com

\begin{abstract}
Using the Social Cognitive Theory as a theoretical framework, this study evaluated a 4-month, individual cognitive-behavioral intervention program to decrease burnout and increase self-efficacy, engagement, and performance among university students. The main objective of the intervention was to decrease the anxiety the students coped with before exams in order to increase their beliefs of self-efficacy. Besides the study group intervened, two control groups were involved (i.e., a "stressed" control group and a "healthy" control group). All 3 groups filled out a questionnaire before the intervention and then again 6 months later ( 2 months after the intervention was completed). The results show that self-efficacy, engagement and performance increased in the intervened group when compared to both control groups. Regarding burnout, decreases were noted in both the intervened and stressed control groups but not in the healthy control group. The implications of the study are discussed, together with its limitations and suggestions for future research.
\end{abstract}

Keywords Self-efficacy $\cdot$ Burnout $\cdot$ Engagement $\cdot$ Intervention

\section{Introduction}

One of the most important concerns in the field of educational psychology is discovering how student performance can be improved. From this perspective, researchers have focused on identifying the best conditions for academic success. Undoubtedly, there is not

This research is supported by grants from the Spanish Ministry of Science \& Technology (\#SEJ2004-02755/ PSIC) and from Bancaixa (\#04I301).

E. Bresó $(\bowtie) \cdot$ M. Salanova

WoNT Research Team, Department of Psychology, Universitat Jaume I, Campus de Riu Sec, s/n, 12017 Castellón, Spain

e-mail: breso@uji.es

W. B. Schaufeli

Utrecht University, Utrecht, The Netherlands 
one unequivocal method for improving students' performance but several studies have enabled researchers to home in on the most efficient determinants of students' performance (Eskew and Faley 1988; Gul and Fong 1993; Naser and Peel 1998; Pintrich and De Groot 1990). These studies pointed out that, for instance, self-expectation of examination results, past achievement in similar tasks, self-efficacy, and the overall level of self-control are related and can be considered antecedents for students' cognitive involvement, well-being, and performance. Past experience in similar tasks (previous academic performance) and self-efficacy beliefs have been nonetheless considered the strongest predictors of students' performance, and their relevance has been confirmed across various samples (Burton and Dowling 2005; Klomegah 2007; Lent et al. 1984; McKenzie and Schweitzer 2001; Multon et al. 1991; Pajares 1996; Zeegers 2004; Zimmerman 2000).

The present study longitudinally examines the effectiveness of a self-efficacy-based intervention among university students and tracks changes in well-being (in terms of burnout and engagement), as well as performance. Bandura's Social Cognitive Theory (SCT) provides the theoretical justification for the postulation that self-efficacy affects academic success by increasing students' sense of well-being and the amount of persistence they demonstrate to master challenging academic tasks, which then results in a more efficient use of acquired knowledge and skills (Bandura 1982).

Self-efficacy is defined as a person's judgment of their capabilities to organize and execute the courses of action required to attain predetermined types of performances. It is concerned not with the skills one has, but rather with the estimation of what one can attain with the skills one currently possesses (Bandura 1986; p. 391). Students who are selfefficacious tend to generate and test alternative courses of action when they do not initially achieve success. They perform better in the classroom because of their elevated levels of effort and persistence and deal more effectively with problematical situations by manipulating the cognitive and emotional processes related to those situations (Bandura 1997). An extensive body of research has shown that academic self-efficacy is directly proportional to undergraduate GPA (Hackett et al. 1992; Lent et al. 1984; Multon et al. 1991) and performance (Bandura 1986; Klomegah 2007; Schunk 1995; Zimmerman and Bandura 1994).

The relevance of self-efficacy in students' learning process is thus undeniable. Another question is how these efficacy beliefs develop and yet another how they can be promoted and strengthened. Students' efficacy beliefs can be altered and promoted in several ways: by mastery experiences, vicarious learning, social persuasion, and specific psychological states (Bandura 1997). Several studies have demonstrated the effectiveness of intervention programs promoting self-efficacy in various contexts. Among female college students (Betz and Schifano 2000), for instance, or with students who participate in on-line learning (Fletcher 2005), not to mention the positive effect on academic achievement (Freedman 1996), and college student learning in general (Wei 2004).

One of the most important sources of efficacy beliefs apart from mastery experience (which refers to past success in comparable tasks), are psychological states. Accordingly, the lower the levels of anxiety, stress, and fatigue are, the higher the levels of self-efficacy will be. When students experience negative thoughts and anxiety with regards their capabilities, these negative affective reactions can themselves further lower perceptions of capability and activate a stress-generating mechanism that reinforces the probability of the inadequate performance they fear. For instance, those students who fear speaking to large groups of people generally develop a lack of confidence in their public speaking skills which leads to poor performance which somewhat falsely justifies and reinforces negative self-efficacy beliefs. 
The psychological state in which students approach a task prefigures their perception of success or failure (Pajares 1996). This is why we focused on the optimization of psychological states when planning the intervention. Our expectation was that changes in psychological state would affect the students' beliefs of self-efficacy, which would in turn affect both performance and future psychological states just as is suggested by Social Cognitive Theory (Bandura 1997).

The aim of the current study is to demonstrate that students' self-efficacy can be increased by interventions that focus on reducing negative psychological states. The expected results of the intervention are decreased student burnout and increased student performance and engagement.

\section{Student burnout and engagement}

Self-efficacy is critical in enhancing students' comfort levels when facing exams. In fact, changes in self-efficacy levels are strongly tied to changes in states of well-being such as burnout and engagement (Salanova et al. 2005). Burnout for students refers to feeling exhausted by one's study load, having a cynical and detached attitude toward one's study, and feeling incompetent as a student (Schaufeli et al. 2002a). Although burnout was originally held to be composed of three dimensions, empirical studies have revealed that exhaustion and cynicism are at its core (Schaufeli and Taris 2005). The third dimension of burnout (lack of efficacy) is thus excluded as previous studies suggest that this dimension plays a different role (Bresó et al. 2007). Indeed, lack of efficacy seems to play an antecedent role in the burnout process rather than comprising an integral element of the burnout syndrome, (Cherniss 1993; Salanova et al. 2003).

Conversely, engagement is defined as a positive, fulfilling, and motivational state of mind related to students' tasks that is characterized by vigor, dedication, and absorption (Schaufeli et al. 2002b). Vigor is characterized by high levels of energy and mental resilience, the willingness to invest effort, and persistence in the face of difficulties. Dedication is characterized by a sense of significance, enthusiasm, inspiration, pride, and challenge. Finally, absorption is characterized by full concentration on one's task. Recent evidence, however, suggests that absorption plays a slightly different role and might be considered a consequence of engagement rather than a constitutive component (Salanova et al. 2003). Accordingly, absorption has been excluded from the present study.

It has been posited that burnout results from successive self-efficacy crises. To begin with, Cherniss (1993) pointed out that burnout develops from feelings of inefficacy or from an 'efficacy crisis,' assuming that the lack of confidence in competences themselves is a crucial factor in burnout development. Leiter (1992) went one step further by essentially considering burnout an 'efficacy crisis.' Contrarily, engagement is considered the increase in motivated behaviour which derives from high levels of self-efficacy. The relationship of effort and motivation with performance is very strong. Success promotes perserverance while failure predisposes people to quitting or giving up (Bandura 1997). Furthermore, the relationships between psychosocial processes, behaviours and the environment are mutually reciprocal. The results of a study carried out by Pintrich and De Groot (1990) even suggest that self-efficacy plays a facilitative role in the process of cognitive engagement. In our study we investigate the effectiveness of a self-efficacy enhancing intervention for increasing engagement and performance and decreasing burnout. We used a quasiexperimental, pre-test/post-test control group design (Cook and Campbell 1979). In addition to an intervened group, we used two control groups of students who did not participate in the intervention. We hypothesized that: 
$\mathbf{H}_{1}$ Compared to the students in the two control groups (that would not participate in the intervention), students in the intervened group would show higher levels of self-efficacy at follow-up.

$\mathbf{H}_{2}$ Compared to the students in both control groups, students in the intervened group would show higher levels of engagement at follow-up.

$\mathbf{H}_{3}$ Compared to the students in both control groups, students in the intervened group would show lower levels of burnout at follow-up.

$\mathbf{H}_{4}$ Compared to students in both control groups, students in the intervened group would show higher levels of academic performance at follow-up.

\section{Method}

Participant recruitment and procedure

The university organized a workshop on dealing with academic stress and anxiety 3 months before the first semester exam period. Every student in the various departments of the university was notified by e-mail and wall posters in the halls also announced it. A total of 66 students expressed interest and attended the workshop where practical exercises allowed them to gauge their anxiety levels. The possibility of taking part in one-on-one sessions was then offered to each student who attended the workshop, and 23 students participated in the individual intervention program, thus constituting our intervened group. The remaining 43 students (who participated in the workshop but did not sign up for the one-on-one intervention program) were asked to complete questionnaires and to participate in the study as a control group. Of them, 27 accepted to participate in the study, constituting our "stressed" control group. We decided on the name "stressed" control group because they had signed up for the same initial workshop on anxiety management as the intervened group and because they possessed similar levels of self-efficacy, well-being and performance (as can be seen in Table 1) to those of the intervened group. A second control group was also used, which we termed "healthy" because of an apparent indifference to the benefits of attending the anxiety workshop. That group was composed of a random sample of comparable students who neither attended the workshop nor, obviously, the subsequent one-on-one sessions. It was made up of 27 students of like age enrolled in similar courses to those in the intervened group sampled from the same university. All participants were asked to fill out the questionnaire twice: first during the workshop (Time 1 [T1]), and again 6 months later, that is, 2 months after the completion of the one-on-one intervention sessions (Time 2 [T2]).

\section{Intervention program}

The intervention consisted of 4 2-hour one-on-one sessions, modeled after the standard cognitive behavioral treatment for anxiety (Barlow et al. 1992; Blowers et al. 1987). Specifically, the problems associated with the anxiety these students experienced with respect to taking exams were treated. The general idea, then, was to improve their psychological state and to develop their emotional competences to cope with exams. This would in turn minimize their feelings of incompetence and the subsequent increases in anxiety when facing exams. The intervention focused on the primary emotional and 
cognitive components of anxiety (Morris et al. 1981), centering on students' intolerance of uncertainty, erroneous beliefs about worry, poor problem orientation, and cognitive avoidance.

This cognitive-behavioral treatment is based on a standard protocol and was applied to students by an experienced therapist (who had 6 years of clinical experience working with university students). Cognitive-behavioral therapy (CBT) was selected because its effectiveness as a treatment for anxiety disorders is well-documented (Barlow 2002). It is one of the most popular types of psychotherapy for overcoming anxiety (Barrowclough et al. 1991). In fact, treatment guidelines now state that CBT should be the first step in treating anxiety (cf. National Institute for Clinical Excellence 2004). The aim was to help students develop coping skills before anxiety took over in order to be able to defeat false or selfdefeating beliefs and promote positive thinking when dealing with exams. The theoretical justification for the treatment is that the anxiety produced by upcoming exams and other required academic work is driven by specific anxious thoughts (e.g., fearful thoughts revolving around symptoms or stemming from situations that provoke anxiety at the time of taking exams) and by a lack of self-confidence defined as a reduced belief in one's ability to carry out certain activities successfully. One example of an anxious thought that was reported by students was: "It is inconceivable that someone in the same circumstances as me could pass such and such exam."

During the intervention it was explained that anxiety can be controlled by a three-step process. The first step is learning to recognize anxious thoughts. The second is seeking realistic and useful alternatives, and the third is taking action to test these alternatives in the course of everyday life. Activity schedules and records of dysfunctional thoughts were used to first locate and identify anxious thoughts and then to develop the skills needed to examine them and to formulate the alternatives to be tested in subsequent behavioral assignments.

Bandura (1997) pointed out that, physiological states such as anxiety, stress, arousal, and fatigue inform efficacy beliefs and that they are considered their sources. Because individuals have the capability to alter their own thinking, self-efficacy beliefs, in turn, also powerfully influence physiological states. Consequently, we assumed that changes in students' anxiety levels will influence their self-efficacy. Additionally, students can gauge their confidence by the emotional state they experience when contemplating a future action.

\section{Participants}

The study included students from various years and degree programs in all three departments of the university. Of the 77 students in the intervened and control groups who filled out the questionnaire at T1, 71 also participated at T2 (92\%), and only these 71 students were included in the final analysis. The final intervened group consisted of 21 students, and the stressed and healthy control groups included 23 and 27 students, respectively (see Fig. 1). Overall, 30 (42.3\%) male and 41 (57.7\%) female students were included. Their mean age was 21.6 years ( $\mathrm{sd}=1.69$; ranging from 18 to 26 ).

\section{Measures}

Self-efficacy was measured with the scale devised by Midgley et al. (2000) which reflects the students' beliefs concerning their future capacity to achieve adequate levels of academic performance. The scale includes 5 items and scores range from 0 (never) to 6 


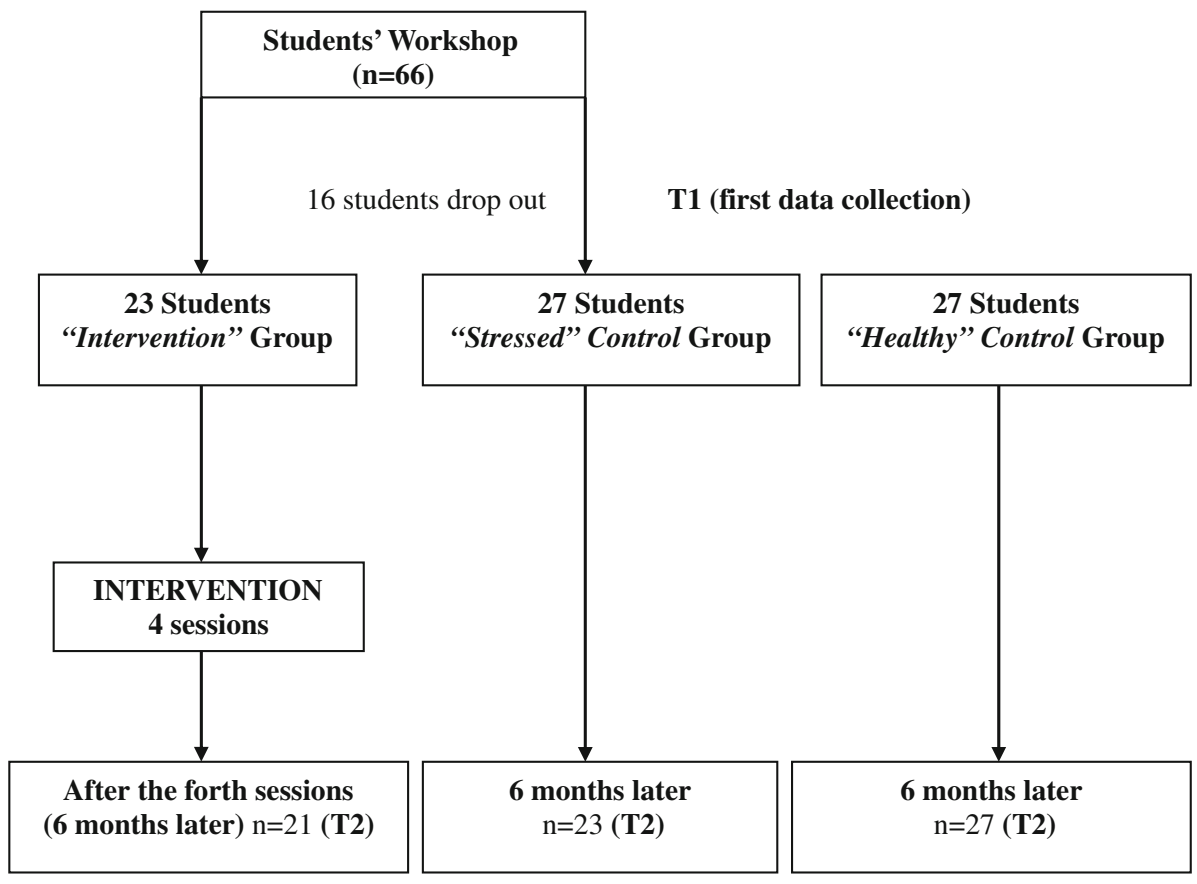

Fig. 1 Flow diagram of participants through each stage of the trial

(always). An example of one item is: 'I will be capable of doing more complicated assignments in class if I try hard enough'. Internal consistencies (Cronbach's $\alpha$ ) for T1 and T2 were .91 and .90, respectively. Questionnaire items are presented in the Appendix.

Academic burnout was assessed with two scales of the MBI-SS (Student Survey) (Schaufeli et al. 2002a, b): exhaustion (EX), comprised of 6 items (e.g., 'I feel emotionally drained by my studies') and cynicism (CY), which includes 4 items (e.g., 'I doubt the significance of my studies'). All items are scored on a 7-point frequency rating scale ranging from 0 ("never") to 6 ("always"). Internal consistencies (Cronbach's $\alpha$ ) for EX at $\mathrm{T} 1$ and $\mathrm{T} 2$ were .85 and .76 , respectively, and were .81 and .70 at $\mathrm{T} 1$ and $\mathrm{T} 2$, respectively, for CY.

Academic engagement was assessed with two scales of the UWES-SS (Student Survey) (Schaufeli et al. 2002a, b). Vigor (VI), which includes 6 items (e.g., 'When I'm doing my work as a student, I feel bursting with energy') and dedication (DE), which includes 5 items (e.g., 'I am enthusiastic about my studies'). All items are scored on a 7-point frequency rating scale ranging from 0 ("never") to 6 ("always"). Several studies have been carried out using MBI-SS and UWES scales to test their validity and reliability along different student samples from various countries (i.e., Spain, Portugal, The Netherlands, and Belgium) (Bresó et al. 2007; Salanova et al. 2005, 2009; Schaufeli et al. 2002a, b) Internal consistencies (Cronbach's $\alpha$ ) for the current study for VI at T1 and T2 were .81 and .89, respectively; and were .72 and .81 at T1 and T2, respectively, for DE.

Performance was measured by estimating the ratio between 'exams taken' and 'exams passed'. This implies that only those students who were enrolled in at least one semester were included in the sample. Marks ranged from 0 (no exam passed) to 1 (all exams passed). The most important factor to consider for our choice of the exam success ratio 
over GPA as a measure of current performance is that among Spanish university students the better measure of success is not how well one does on an exam, but how many exams one passed. This is due in large part due to the structure that allows students to opt out of taking some final exams at the end of the school year to take them after the summer vacation without penalty. This is the space where students employ their strategic resources to the fullest: some purposefully absent themselves from classes they believe themselves capable of passing after a summer of independent study in order to concentrate on the courses they deem most important. Furthermore, GPA is not deemed as important by students, professors, or employers as is the rapidity with which the student completes the required courses and obtains their degree. In other words, the amount of exams passed is a much more valid indicator of performance than GPA.

\section{Results}

Descriptive and correlation analyses

Tables 1 and 2 show the means, standard deviations, and inter-correlations of the outcome measures in the 3 groups. As is seen, the expected correlations are found (e.g. cynicism and exhaustion as well as vigor and dedication are positively and significantly correlated). Regarding reliability, all of the Cronbach $\alpha$ values meet the more stringent criterion of 80 (Henson 2001), except dedication $(\alpha=.72)$ at T1, exhaustion $(\alpha=.76)$ at T2, and cynicism $(\alpha=.70)$ at $\mathrm{T} 2$, yet they do nonetheless meet the more common validity threshold criterion of .70 (Nunnaly and Bernstein 1994) (Table 2).

Hypothesis tests

First, a multivariate test including all the dependent variables (i.e. self-efficacy, exhaustion, cynicism, vigor, dedication, and performance) was performed across all 3 groups. The result showed a significant multivariate effect of time [Wilks' lambda $=.237$; $F(6.63)=33.76 ; p<.001)$ ] and group [Wilks' lambda $=.327 ; F(12.126)=7.87$; $p<.001)$ ], and a significant time $\times$ group interaction effect [Wilks' lambda $=.17$; $F(12.126)=14.96 ; p<.001)]$.

Table 1 Means and standard deviations of the study variables at T1 and T2 for each group

\begin{tabular}{|c|c|c|c|c|c|c|c|c|c|c|c|c|}
\hline \multirow[t]{3}{*}{ Variable } & \multicolumn{4}{|c|}{$\begin{array}{l}\text { Intervened group } \\
(N=21)\end{array}$} & \multicolumn{4}{|c|}{$\begin{array}{l}\text { Stressed control group } \\
(N=23)\end{array}$} & \multicolumn{4}{|c|}{$\begin{array}{l}\text { Healthy control group } \\
(N=27)\end{array}$} \\
\hline & \multicolumn{2}{|l|}{$\mathrm{T} 1$} & \multicolumn{2}{|l|}{$\mathrm{T} 2$} & \multicolumn{2}{|l|}{$\mathrm{T} 1$} & \multicolumn{2}{|l|}{$\mathrm{T} 2$} & \multicolumn{2}{|l|}{$\mathrm{T} 1$} & \multicolumn{2}{|l|}{$\mathrm{T} 2$} \\
\hline & $M$ & SD & $M$ & SD & $M$ & SD & $M$ & SD & $M$ & SD & $M$ & SD \\
\hline Self-efficacy & 3.28 & .96 & 4.45 & .55 & 3.25 & 1.05 & 3.07 & .66 & 4.20 & .84 & 4.12 & .81 \\
\hline Exhaustion & 3.50 & .95 & 2.10 & .67 & 3.49 & .91 & 2.06 & .65 & 2.70 & 1.32 & 2.64 & .93 \\
\hline Cynicism & 2.81 & .75 & 1.65 & .49 & 2.77 & .73 & 1.66 & .54 & 1.45 & 1.17 & 1.54 & 1.11 \\
\hline Vigor & 2.80 & .86 & 4.05 & .75 & 2.72 & .67 & 2.59 & .60 & 3.73 & .81 & 3.67 & .93 \\
\hline Dedication & 3.51 & .87 & 4.21 & .80 & 3.43 & .81 & 2.94 & .52 & 4.05 & .89 & 3.96 & .92 \\
\hline Performance & 5.25 & 1.30 & 6.84 & 1.33 & 5.92 & 1.57 & 6.10 & 1.54 & 7.22 & .89 & 7.76 & 1.01 \\
\hline
\end{tabular}




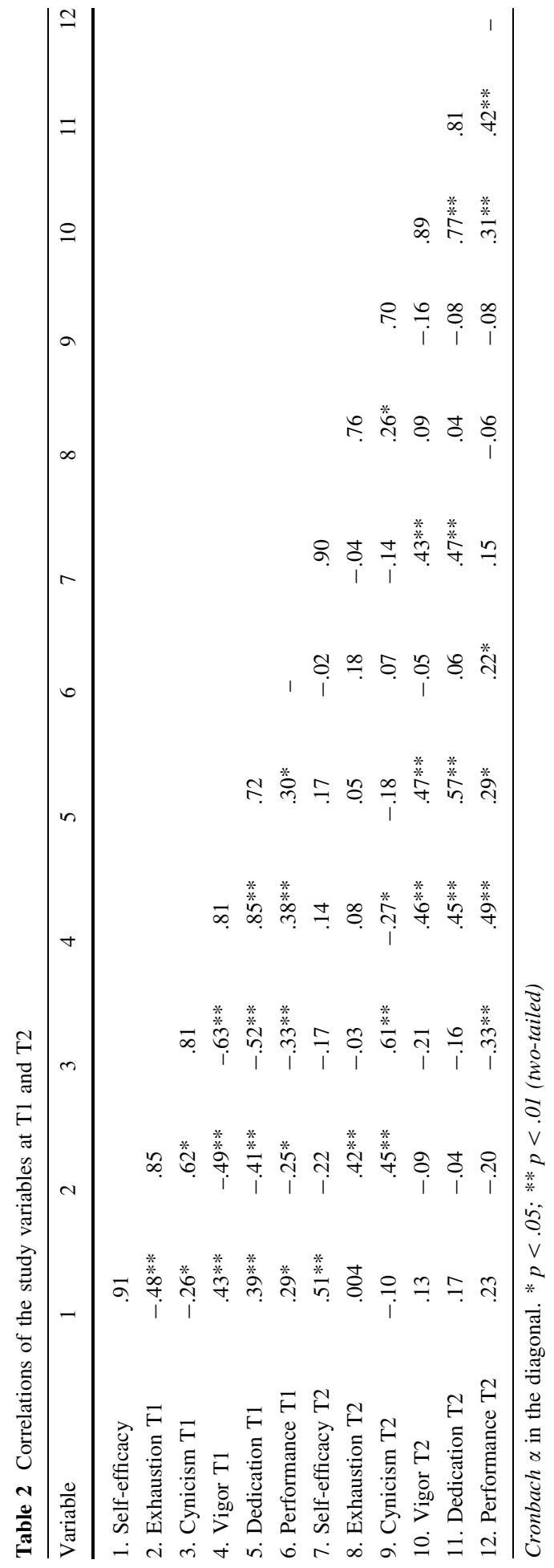


It was hypothesized that the intervention would have a positive effect on self-efficacy (Hypothesis 1) and engagement (Hypothesis 2), a negative effect on burnout (Hypothesis 3 ), and a positive effect on performance (Hypothesis 4). Subsequent univariate tests revealed significant time $\times$ group interaction effects for self-efficacy $(F=21.61 ; d f=2$; $p<.001)$; exhaustion $(F=19.68 ; d f=2 ; p<.001)$; cynicism $(F=27.6 ; d f=2 ; p<$ $.001)$; vigor $(F=22.73 ; d f=2 ; p<.001)$; dedication $(F=14.67 ; d f=2 ; p<.001)$; and performance $(F=13.13 ; d f=2 ; p<.033)$. These significant interaction effects are graphically displayed in Figs. 2-5 to facilitate interpretation. As seen, the levels of selfefficacy in Fig. 2 of those students who took part in the intervention program increased significantly $(F=23.89 ; d f=40 ; p<.001)$, whereas no significant increase was observed for the "stressed" control group $(F=.51 ; d f=44$; n.s. $)$ or the "healthy" control group $(F=.13 ; d f=52$; n.s.). Hypothesis 1 , then, is confirmed.

A similar pattern was observed for vigor. As Fig. 3 depicts, the levels of vigor of the students in the intervened group increased significantly $(F=25.81 ; d f=40 ; p<.001)$, whereas no significant increase was observed for the "stressed" control group $(F=.48$; $d f=44$; n.s. $)$ or the "healthy" control group $(F=.06$; $d f=52$; n.s.). Regarding the other dimension of engagement, dedication, a significant increase was observed in the intervened group $(F=7.29 ; p=.01)$, but a significant decrease was observed in the "stressed"

Fig. 2 Two-way interaction of Group $\times$ Time on student selfefficacy

Fig. 3 Two-way interaction of Group $\times$ Time on vigor
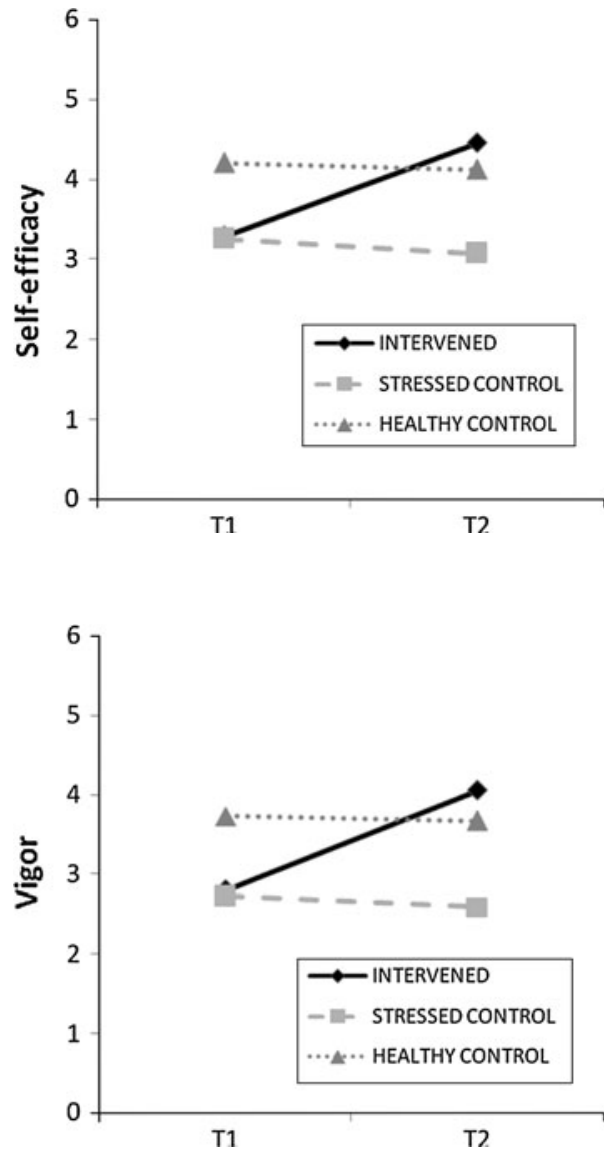
Fig. 4 Two-way interaction of Group $\times$ Time on dedication

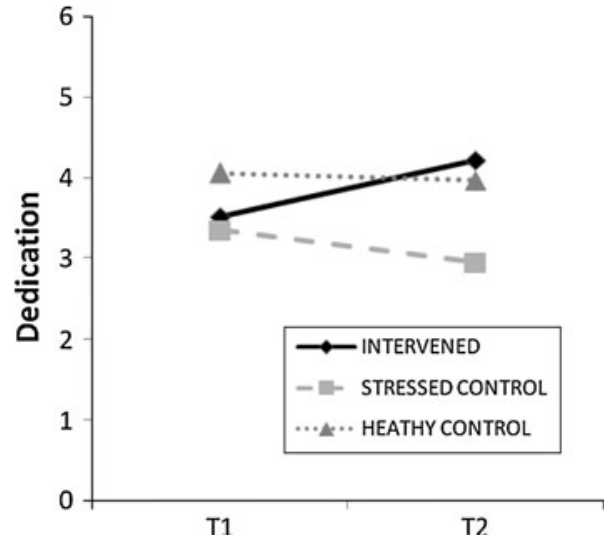

Fig. 5 Two-way interaction of Group $\times$ Time on exhaustion

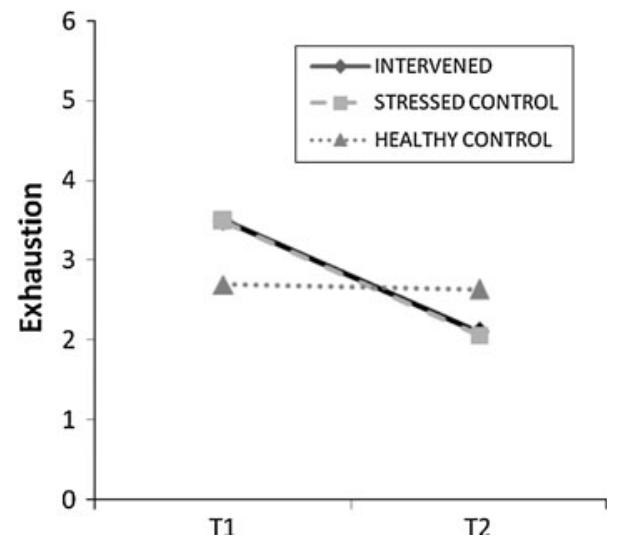

control group $(F=8.54 ; p=.018)$, while no significant increase was noted for the "healthy" control group $(F=.15 ; d f=52 ;$ n.s.) (Fig. 4). Hypothesis 2 postulating a significant positive effect of the intervention on levels of engagement is thus also confirmed.

The results regarding burnout differ slightly from the expected results. As expected and displayed in Fig. 5, the levels of exhaustion of the intervened group decreased significantly $(F=30.34 ; d f=40 ; p<.001)$, whereas no significant decrease was observed in the "healthy" control group ( $F=.036 ; d f=52 ;$ n.s. $)$. Contrary to expectations, however, the levels of exhaustion of the "stressed" control group also decreased significantly $(F=46.06 ; d f=44 ; p<.001)$, results for cynicism were similar (Fig. 6), showing a significant decrease in the intervened group $(F=35.87 ; d f=40 ; p<.001)$, no significant change in the "healthy" control group $(F=.088 ; d f=52$; n.s. $)$, and a significant decrease in the stressed group $(F=34.19 ; d f=44 ; p<.001)$. Thus, the positive effect on the two dimensions of burnout was not restricted to the intervened group, but also occurred in the "stressed" control group. Hypothesis 3 is therefore supported for the intervened group and "healthy" control group, but not for the "stressed" control group.

Finally, as displayed in Fig. 7, the performance of the intervened group increased significantly $(F=15.21 ; d f=40 ; p<.001)$, whereas no change in performance was observed for the "stressed" control group $(F=.16 ; d f=44$; n.s.). Contrary to expectations, 
Fig. 6 Two-way interaction of Group $\times$ Time on cynicism

Fig. 7 Two-way interaction of Group $\times$ Time on Performance
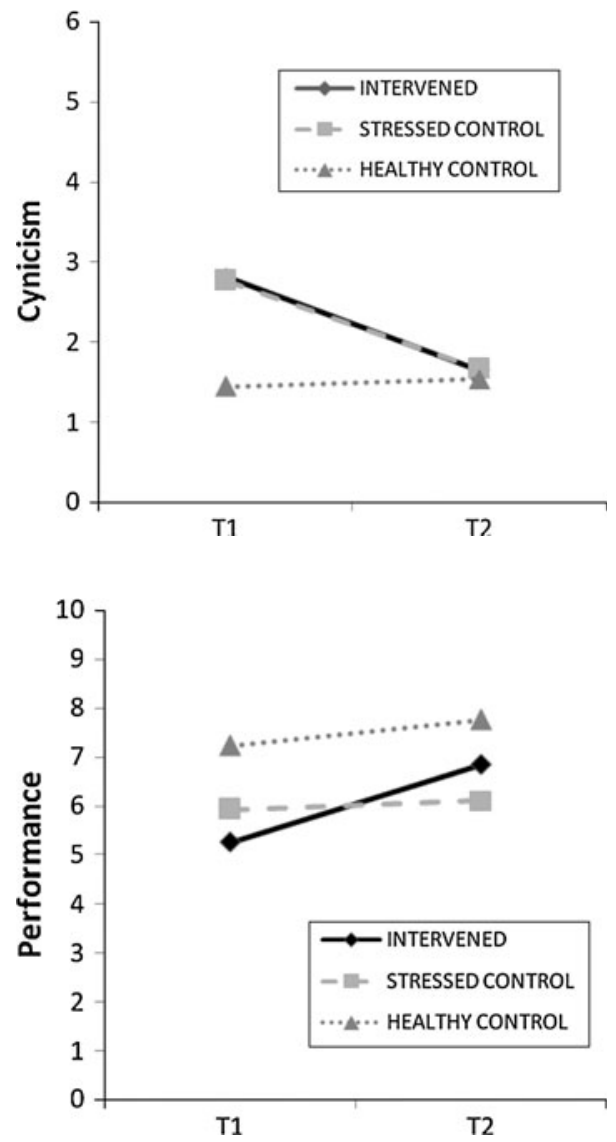

however, the performance levels of the "healthy" control group also increased significantly $(F=4.57 ; d f=52 ; p=.037)$. Hence, Hypothesis 4 is confirmed for the intervened group and the "stressed" control group, but not for the "healthy" control group.

In addition, it is important to note that the initial levels of self-efficacy, engagement (vigor and dedication), burnout (exhaustion and cynicism), and performance differed significantly between the "healthy" control group and the intervened group on one side and the "stressed" control group on the other. At T1, levels of self-efficacy [ $F=12.87$; $d f=48 ; p<.001),(F=12.62 ; d f=46 ; p<001)]$, vigor $[(F=12.70 ; d f=48 ; p<$ $.001 ; \quad F=14.91 ; \quad d f=46 ; \quad p<.001)]$, dedication, $[(F=6.47 ; \quad d f=48 ; \quad p<.01 ;$ $F=4.39 ; \quad d f=46 ; \quad p<.04)]$, exhaustion $[(F=5.85 ; \quad d f=48 ; p<.02 ; \quad F=5.45 ;$ $d f=46 ; p<.02)]$ cynicism $[(F=21.75 ; d f=48 ; p<.001 ; F=21.14 ; d f=46 ; p<$ $.001)]$ and performance $[(F=13.52 ; d f=48 ; p<.001 ; F=38.79 ; d f=46 ; p<.001)]$ were significantly higher (in terms of self-efficacy, vigor, dedication, and performance) and lower (in terms of exhaustion and cynicism), for the healthy group as compared to the intervened and the "stressed" groups, respectively. On the other hand, differences at T1 between the intervened group and the stressed control group in all of the outcome variables were not significant. This means that the stressed group and the intervened group are comparable as far as levels of self-efficacy, engagement, burnout, and performance are concerned. 
Finally, effect sizes were estimated for all the outcome variables using Cohen's $d$ coefficient (pooled effect size) (Cohen 1988, 1992). The results showed "medium" effect sizes for self-efficacy $(r=-.59)$, exhaustion $(r=.65)$, cynicism $(r=.68)$, vigor $(r=$ $-.61)$; and performance $(r=-.52)$, and a "small" effect size for dedication $(r=-.34)$. Overall, then, effect sizes are relatively strong and lie in the expected range.

\section{Discussion}

The present study investigated the effects of a cognitive behavioral intervention program to increase self-efficacy, engagement, and performance, and to decrease burnout among university students. The study design included one intervened group and two control groups: one consisting of supposedly "stressed" students with similar baseline scores for the study variables to the intervened group, and another control group consisting of "healthy" students who scored more favorably on the baseline scores.

Using Analyses of Variance comparing the two control groups, the intervened group presented as expected higher levels of self-efficacy at T2 (Hypothesis 1), higher levels of engagement (Hypothesis 2), and higher levels of performance (Hypothesis 4).Two unexpected results, however, were obtained and furthermore the lowest levels of burnout did not pertain to the students from the intervened group (Hypothesis 3 ).

The first unexpected result indicates that decreases in the dimensions of burnout not only affected the intervened group over time, but also the "stressed" control group, as the interaction effects depicted in Figs. 5 and 6 show. Since students were not randomly distributed across groups, this effect could be due to the effect of regression to the mean. This statistical phenomenon is often observed in groups pre-selected for scores below the mean on a measurement because it is subsequently more likely that the average score improves, purely by chance, when the measurement is repeated (Morton and Torgerson 2003). The regression to the mean effect could have occurred in our study since the students from the "stressed" control group are not representative of the average student population. These students initially scored (T1) higher for burnout, lower for self-efficacy, and lower for engagement than the "healthy" control group which was randomly sampled from an unspecified population of students (Table 1). If this were the case however, it should have also affected the "stressed" control group's engagement and self-efficacy scores. Nonetheless, the difference was only apparent in the two burnout dimensions. The regression to the mean effect, then, does not seem to adequately explain the time effect found in the burnout dimensions.

Instead, we speculate that although the students from the "stressed" control group did not take part in the intervention, they used alternative ways to cope with their anxiety problems (such as consulting their friends, family or other counseling staff, dealing with their anxiety using self-help techniques, or even by seeking professional help). Students from the "stressed" control group may have used some alternative way to reduce their levels of burnout and to increase their levels of engagement between T1 and T2. Unfortunately, we did not ask those members of the "stressed" group about such alternatives. This possible explanation, namely that of a student or students actively seeking help or support, is more congruent with the results obtained than the regression to the mean effect and is also consistent with results found in previous research. For instance, in the burnout intervention study among 110 female white-collar workers carried out Hätinen et al. (2004), it was found that cynicism scores spontaneously decreased not only in the 
intervention groups but also in the control group. The authors argue that this effect was due to the initiative of participants to employ self-help techniques during their period of waiting. In another intervention study involving dentists, Te Brake et al. (2001) noted that the participants who did not take part in the intervention also ended up showing less exhaustion. The authors only checked for self-initiatives at the first post-test and so argued that the control group could have taken subsequent actions in order to explain the positive shift found. In light of these conclusions, it could be useful to carry out further research on the measures stressed students undertook in order to deal with their anxiety after the workshop.

The second unexpected result was that improved performance at T2 was not only noted in the intervened group, but indeed all of the groups improved their performance in T2, which contradicts Hypothesis 4. Contrary to what we hypothesized, the "healthy" control group performed best (Table 1). As Fig. 7 indicates, however, the greatest slope of the lines tracking difference in performance between $\mathrm{T} 1$ and $\mathrm{T} 2$ in performance pertained to that of the intervened group. Furthermore, we hold that the performance improvement observed at T2 will enhance students' future self-efficacy (inasmuch as it will constitute mastery experience), and performance will most likely continue to improve over future exam periods for the students who took part in the intervention. From this perspective, the effect at T2 should be considered a short-term effect of the increased self-efficacy in the analysis of the effect of self-efficacy on future performance. This idea is congruent with the results of a study carried out by Llorens et al. (2007) that suggests there is a positive gain spiral in which efficacy beliefs play a central-mediating role between past and future outcomes by way of engagement. Increases in self-efficacy, that is, lead to increases in engagement which enhance performance at $\mathrm{T} 1$, and the added performance at $\mathrm{T} 1$ influences self-efficacy at T2, which once again spurs the 'upward' process.

\section{Theoretical implications}

The results demonstrate the effectiveness of intervention focused on students' psychological states and their levels of self-efficacy and engagement. Moreover, the use of two different control groups in the study design revealed the success of the intervention, particularly in terms of promoting engagement. The effect found was exclusively significant for the intervened group in the case of engagement, whereas the changes in burnout also occurred in the "stressed" control group. The intervention thus had the expected effect not simply on self-efficacy, but only for engagement and not for burnout. This highlights the power of self-efficacy in the promotion of positive states of mind (Salanova et al. 2005). This result is also supported by previous research undertaken in the Job DemandResources Model (JD-R) (Demerouti et al. 2001). Xanthopoulou et al. (2007), for instance, demonstrated that self-efficacy affects the motivational process that leads to engagement, but not the health impairment process that leads to burnout.

All hypotheses were confirmed for the intervened group and also for the "healthy" control group for self-efficacy and engagement. The effect that the intervention had on self-efficacy, then, meant that students displayed significant increases in their levels of vigor, dedication, and intervention also enhanced their performance at $\mathrm{T} 2$. This finding experimentally supports the supposition increasing student self-efficacy is a key factor in triggering a positive process whose result is increased student performance, as corroborated by previous cross-sectional studies. The current study buttresses the theory of a 
positive relationship between self-efficacy, engagement, and performance in student populations (see Llorens et al. 2007; Salanova et al. 2005).

\section{Practical implications}

The advisability of programming or implementing counseling activities such as workshops and interventions to promote healthy psychological states in universities is the most relevant practical implication of the present study. The fact that, although both the "stressed" control group and the intervened group shared similar levels of burnout, self-efficacy and engagement scores, only the intervened group improved their scores for self-efficacy and the engagement dimensions, suggests that intervention played an active role in promoting positive states of mind, exemplified in terms of efficacy beliefs, vigor and dedication to their studies. More university counseling programs developed on a larger scale might very well improve students' psychological states and therefore enhance positive states of mind.

\section{Limitations and future research}

On the one hand, the use of self-reports has been considered an important limitation in studies such as the present. Self-reports are considered to be influenced by subjective factors (Spector 1992), well-being (Coyne 1994), and individual differences (Burke et al. 1993). Moreover, the variables assessed in the study run the risk of being inflated by common method variance. These factors notwithstanding, Spector (2006) provides empirical evidence against the belief that the method itself produces systematic variance in observations that inflates correlations by any significant degree. He argues that using selfreported measures is not in itself responsible for design weaknesses.

On the other hand, since the students in the intervened group knew that the intervention focused on self-efficacy, burnout, engagement and performance, they might have answered T2 questionnaires with a 'positive bias.' The T2 results in the intervened group would then have been exaggerated because of expectation (Staw 1975). In theory, this effect could be due to a demand characteristic (Orne 1962), a possible bias due to the fact that students participating in the intervention were expected to make positive changes. This is not likely, however, because the positive effect was not only found in engagement but also in performance, which is a more "objective" variable and less likely to be affected by this answer tendency (see Frese and Zapf 1988). Even though the measures of engagement might have been overstated, then, the measures of performance were nonetheless stronger (in terms of objectivity), and such measures support the overall results obtained.

A third limitation to the external validity of the present study is its relatively small sample size. In spite of the limited sample size, however, the power of the effects found was strong enough to attain statistical significance and, even more importantly, the estimated pooled effect sizes (Cohen $d$ ) in each outcome variable were moderately strong with values ranging between .34 and .68 .

For further research, it would be useful to employ larger student sample sizes and longitudinal designs that include at least three waves of evaluation in order to gauge the mediating role of self-efficacy and any potential self-efficacy well-being performance spirals. The use of a 3-wave sample might reveal the real causal relationship between selfefficacy, engagement, and performance that we speculate is operative in the current research. Additionally, follow-up measures for the control groups between T1 and T2 would be useful in order to gain more insight into how students respond to psychological states and to reduce the chances of encountering unexpected effects. 
Final note

In conclusion, this is one of the few studies that have shown that self-efficacy-based intervention has positive effects on students' well-being and performance using a quasiexperimental design. Our study demonstrates the effectiveness of intervention programs to promote healthy psychological states and engagement among students in order to improve performance. The workshop effectively identified and recruited "at risk" students for participation in a cognitive-behavioral intervention program. Most importantly, the oneon-one cognitive-behavioral sessions proved effective in improving both engagement and performance.

Acknowledgments Special thanks to Bradley Hayes for his disinterested and valuable support as well as his contribution to this paper.

Open Access This article is distributed under the terms of the Creative Commons Attribution Noncommercial License which permits any noncommercial use, distribution, and reproduction in any medium, provided the original author(s) and source are credited.

\section{Appendix}

Academic self-efficacy

I will be able to properly use the practical skills I learned over the last academic year I will be able to understand the most difficult subjects this academic year If I try hard enough, I will be able to complete every task in class I will be able to learn in class, even the most complicated concepts If I try hard, I will be able to do the most difficult tasks related to my studies

\section{References}

Bandura, A. (1982). Self-efficacy mechanism in human agency. American Psychologist, 37(2), $122-147$.

Bandura, A. (1986). Social foundations of thought and action: A social cognitive theory. Englewood Cliffs, NJ: Prentice-Hall Inc.

Bandura, A. (1994). Self-efficacy. In V. S. Ramachaudran (Ed.), Encyclopedia of human behavior (Vol. 4, pp. 71-81). New York: Academic Press. (Reprinted in H. Friedman [Ed.], Encyclopedia of mental health. San Diego: Academic Press, 1998).

Bandura, A. (1997). Self-efficacy: The exercise of control. New York: Freeman \& Co.

Barlow, D. H. (2002). Anxiety and its disorders: The nature and treatment of anxiety and panic (2nd ed.). New York: Guilford Press.

Barlow, D. H., Rapee, R. M., \& Brown, T. A. (1992). Behavioral treatment of generalized anxiety disorder. Behavior Therapy, 23, 551-570.

Barrowclough, C., King, P., Colville, J., Russell, E., Burns, A., \& Tarrier, N. (1991). A randomized trial of the effectiveness of cognitive-behavioral therapy and supportive counseling for anxiety symptoms in older adults. Journal of Consulting and Clinical Psychology, 69, 756-762.

Betz, N., \& Schifano, R. S. (2000). Evaluation of an intervention to increase realistic self-efficacy and interests in college women. Journal of Vocational Behavior, 56, 35-52.

Blowers, C., Cobb, J., \& Mathews, A. (1987). Generalized anxiety: A controlled treatment study. Behaviour Research and Therapy, 25, 493-502.

Bresó, E., Salanova, M., \& Schaufeli, W. B. (2007). In search of the 'third dimension' of burnout: Efficacy or inefficacy? Applied Psychology: An International review, 56, 460-478. 
Burke, M. J., Brief, A. P., \& George, J. M. (1993). The role of negative affectivity in understanding relations between self-reports of stressors and strains: A comment on the applied psychology literature. Journal of Applied Psychology, 78, 402-412.

Burton, J., \& Dowling, D. (2005). In search of the key factors that influence student success at university. Paper presented to the Higher Education Research and Development Society of Australia (HERDSA) Conference, Sydney, 3rd-6th July, 2005.

Cherniss, C. (1993). Role of professional self-efficacy in the etiology and amelioration of burnout. In W. B. Schaufeli \& Ch. Maslach (Eds.), Professional burnout: Recent developments in theory and research. Series in applied psychology: Social issues and questions (pp. 135-149). Washington, DC: Taylor \& Francis.

Cohen, J. (1988). Statistical power analysis for the behavioral sciences (2nd ed.). Mahwah, NJ: Erlbaum.

Cohen, J. (1992). A power primer. Psychological Bulletin, 112, 155-159.

Cook, T. D., \& Campbell, D. T. (1979). Quasi-experimentation: Design and analysis issues for field settings. Chicago: Rand McNally.

Coyne, J. C. (1994). Self-reported distress: Analog or ersatz depression. Psychological Bulletin, 116, 29-45.

Demerouti, E., Bakker, A. B., Nachreiner, F., \& Schaufeli, W. B. (2001). The job demands-resources model of burnout. Journal of Applied Psychology, 86, 499-512.

Eskew, R. K., \& Faley, R. H. (1988). Some determinants of student performance in the first college-level financial accounting course. The Accounting Review, 63(1), 137-147.

Fletcher, K. (2005). Evaluating an intervention to build online learning self-efficacy. Dissertation Abstracts. International Section A: Humanities and Social Sciences, 66(3-A), 914.

Freedman, A. (1996). Effects of a multicomponent group intervention on the self-efficacy and academic achievement of at-risk undergraduates. Dissertation Abstracts. International Section A: Humanities and Social Sciences, 57(6-A), 2380.

Frese, M., \& Zapf, D. (1988). Methodological issues in the study of work stress: Objective vs subjective measurement of work stress and the question of longitudinal design studies. In C. L. Cooper \& R. Payne (Eds.), Causes, coping, and consequences of stress at work (pp. 375-409). West Sussex, England: John Wiley.

Gul, F., \& Fong, S. (1993). Predicting success for introductory accounting students; some further Hong Kong evidence. Accounting Education: An International Journal, 2(1), 33-42.

Hackett, G., Betz, N. E., Casas, J. M., \& Rocha-Singh, I. A. (1992). Gender, ethnicity, and social cognitive factors predicting the academic achievement of students in engineering. Journal of Counseling Psychology, 39(4), 527-538.

Hätinen, M., Kinnunen, U., Pekkonen, M., \& Aro, A. (2004). Burnout patterns in rehabilitation: Short-term changes in job conditions, personal resources, and health. Journal of Occupational Health Psychology, 9, 220-237.

Henson, R. K. (2001). Understanding internal consistency reliability estimates: A conceptual primer on coefficient alpha. Measurement and Evaluation in Counseling and Development, 34, 177-189.

Klomegah, R. Y. (2007). Predictors of academic performance of university students: An application of the goal efficacy model. College Student Journal, 41(2), 407-415.

Leiter, M. P. (1992). Burn-out as a crisis in self-efficacy: Conceptual and practical implications. Work \& Stress, 6, 107-115.

Lent, R. W., Brown, S. D., \& Larkin, K. C. (1984). Relation of self-efficacy expectations to academic achievement and persistence. Journal of Counseling Psychology, 31(3), 356-362.

Llorens, S., Salanova, M., Schaufeli, W. B., \& Bakker, A. (2007). Does a positive gain spiral of resources, efficacy beliefs and engagement exist? Computers in Human Behavior, 23, 825-841.

McKenzie, K., \& Schweitzer, R. (2001). Who succeeds at university? Factors predicting academic performance in first year Australian university students. Higher Education Research \& Development, 20(1), 21-33.

Midgley, C., Maehr, M. L., Hruda, L. Z., Anderman, E., Anderman, L., Freeman, K. E., et al. (2000). Manual for patterns of adaptative learning scales. Ann Arbor: University of Michigan Press.

Morris, W., Davis, M. A., \& Hutchings, C. H. (1981). Cognitive and emotional components of anxiety: Literature review and a revised worry-emotionality scale. Journal of Educational Psychology, 73(4), $541-555$.

Morton, V., \& Torgerson, D. J. (2003). Effect of regression to the mean on decision making in health care. British Medical Journal, 326, 1083-1084.

Multon, K. D., Brown, S. D., \& Lent, R. W. (1991). Relation of self-efficacy beliefs to academic outcomes: A meta-analytic investigation. Journal of Counseling Psychology, 38(1), 30-38. 
Naser, K., \& Peel, M. J. (1998). An exploratory study of the impact of intervening variables on student performance in a principles of accounting course. Accouring Education: An International Journal, $7(3), 209-223$.

National Institute for Clinical Excellence. (2004). Anxiety: Management of anxiety (panic disorder, with or without agoraphobia, and generalized anxiety disorder) in adults in primary, secondary and community care (2004) Retrieved from www.nice.org.uk/CG022quickrefguide.

Nunnaly, J. C., \& Bernstein, I. H. (1994). Psychometric theory (3rd ed.). New York, NY: McGraw-Hill.

Orne, M. T. (1962). On the social psychology of the psychology experiment: With particular reference to demand characteristics and their implications. American Psychologist, 17, 776-783.

Pajares, F. (1996). Self-efficacy beliefs in academic settings. Review of Educational Research, 66(4), 543578.

Pintrich, P. R., \& De Groot, E. V. (1990). Motivational and self-regulated learning components of classroom academic performance. Journal of Educational Psychology, 82, 33-40.

Salanova, M., Bresó, E., \& y Schaufeli, W. B. (2005). "Hacia un modelo espiral de la autoeficacia en el estudio del burnout y del engagement" [Towards a Spiral model of Self-efficacy in the study of Burnout and Engagement]. Ansiedad y Estrés, 11(2), 215-231.

Salanova, M., Llorens, S., Cifre, E., Martínez, I., \& Schaufeli, W. B. (2003). Perceived collective efficacy, subjective well-being and task performance among electronic work groups: An experimental study. Small Group Research, 34, 43-73.

Salanova, M., Schaufeli, W. B., Martinez, I., \& Breso, E. (2009). How obstacles and facilitators predict academic performance: The mediating role of study burnout and engagement. Anxiety, Stress, \& Coping, 26, 1-18.

Schaufeli, W. B., Martinez, I., Marques-Pinto, A., Salanova, M., \& Bakker, A. (2002a). Burnout and engagement in university students. Journal of Cross-Cultural Psychology, 33(5), 464-481.

Schaufeli, W. B., Salanova, M., Gonzalez-Roma, V., \& Bakker, A. (2002b). The measurement of engagement and burnout: A two sample confirmatory factor analytic approach. Journal of Hapiness Studies, 3(1), 71-92.

Schaufeli, W. B., \& Taris, T. W. (2005). The conceptualization and measurement of burnout: Common ground and worlds apart. Work \& Stress, 19, 256-262.

Schunk, D. H. (1995). Self-efficacy and education and instruction. In J. E. Maddux (Ed.), Self-efficacy, adaptation, and adjustment: Theory, research, and application (pp. 281-303). New York: Plenum Press.

Spector, P. E. (1992). A consideration of the validity and meaning of self-report measures of job conditions. In C. L. Cooper \& I. T. Robertson (Eds.), International review of industrial and organizational psychology (pp. 123-151). Chichester, England: Wiley.

Spector, P. E. (2006). Method variance in organizational research. Organizational Research Methods, 9(2), 221-232.

Staw, B. M. (1975). Atribition of the "causes" of performance: A general alternative interpretation of crosssectional research on organizations. Organizational Behavior and Human Performance, 13, 414-432.

Te Brake, J. H. M., Gorter, R. C., Hoogstraten, J., \& Eijkman, M. A. J. (2001). Burnout intervention among Dutch dentists: Long-term effects. European Journal of Oral Sciences, 109, 380-387.

Wei, Y. (2004). The measurement and intervention of college students' learning self-efficacy. Psychological-Science, 27(4), 905-908.

Xanthopoulou, D., Bakker, A., \& Demerouti, E. (2007). The role of personal resources in the job demandsresources model. International Journal of Stress Management, 14(2), 121-141.

Zeegers, P. (2004). Student learning in higher education: A path analysis academic achievement in science. Higher Education Research \& Development, 23(1), 35-56.

Zeldin, A. L., \& Pajares, F. (1997). Against the odds: Self-efficacy beliefs of women with math-related careers. Paper presented at the meeting of the American Educational Research Association, Chicago.

Zimmerman, B. (2000). Self-efficacy: An essential motive to learn. Contemporary Educational Psychology, $25,82-91$.

Zimmerman, B. J., \& Bandura, A. (1994). Impact of self-regulatory influences on writing course attainment. American Educational Research Journal, 31(4), 845-862. 